\title{
Impact of the COVID-19 Epidemic: Scenario in a Tropical Environment
}

\author{
Som Sharma ${ }^{1}$ and Prashant Kumar ${ }^{2}$
}

\begin{abstract}
The present study investigates the association of COVID-19 virus transmission with atmospheric and air quality parameters including temperature, moisture, particulate matter $(\mathrm{PM})$, and nitrogen dioxide $\left(\mathrm{NO}_{2}\right)$. The variation in the reproduction number $\left(R_{0}\right.$; a measure to reflect the infectiousness of a disease) for COVID-19 transmission is evaluated for tropical and mid-latitude countries. Results suggest that mid-latitude atmospheric conditions are more favorable to COVID-19 transmission as compared to the tropical atmosphere. The peak value of $R_{0}$ was noted as 2.35 (95\% CI 2.11-2.57) on 23 March 2020, and it decreased significantly due to strict lockdown from 25 March 2020 to 1 April 2020. The $R_{0}$ value further increased after 1 April 2020 over India, and the value of $R_{0}$ was found to be greater than 1 , indicating that the epidemic was active. Moreover, the present study was also extended to understand the impact of global/Indian lockdowns on air quality and $R_{0}$ value for COVID-19 transmission. Our findings revealed that the global/Indian lockdown helped reduce the $R_{0}$ value of COVID-19 transmission, which is associated with atmospheric and air quality parameters. Furthermore, a significant reduction in air pollution over India during the lockdown also has implications for continued exploration of clean energy prospects in the future.
\end{abstract}

Keywords: COVID-19, reproduction number, air quality, temperature, moisture.

\section{Introduction}

The coronavirus disease-2019 (COVID-19) pandemic, also known as 2019-nCoV, is spreading worldwide, including in India (Isaifan, 2020). The reproduction number $\left(R_{0} ; R\right.$ naught $)$ is generally used

Supplementary Information The online version contains supplementary material available at https://doi.org/10.1007/s00024021-02793-0.

1 Space and Atmospheric Sciences Division, Physical Research Laboratory, Ahmedabad 380009, India. E-mail: somkumar@prl.res.in

2 Atmospheric Sciences Division, Atmospheric and Oceanic Sciences Group, EPSA, Space Applications Centre, ISRO, Ahmedabad, India. E-mail: kam3545@gmail.com as an indication of the transmissibility of a virus and a widely used metric to study the dynamics of infectious disease (Delamater et al., 2019; Obadia et al., 2012). The $R_{0}$ estimates the speed at which a disease is capable of spreading in a population, i.e. it represent the expected number of secondary (new) infections produced by an infectious person in a completely susceptible population (Sahin et al., 2020). Mathematically, $R_{0}$ is a threshold for the stability of a disease-free equilibrium and is related to the peak and final size of an epidemic. The increase in the infected population is represented by $R_{0}>1$, and transmission of influenza likely to decrease is represented by $R_{0}<1$ (Biggerstaff et al., 2014; Cintrón-Arias et al., 2020; Van den Driessche \& Watmough, 2008). Earlier studies estimated the basic reproductive number for COVID-19 in the range of 1.4-6.49, with a mean of 3.28 over Wuhan, China (Liu et al., 2020). Zhang et al. (2020) calculated the median of $R_{0}$ for COVID-19 was about 2.28 (2.06-2.52) during the early stage experienced on the Diamond Princess cruise ship.

Various atmospheric parameters including temperature, moisture, and air quality are also essential to study the influence and transmission of COVID-19. Previous studies have reported that temperature, moisture, and precipitation conditions of the atmosphere can affect the transmission of influenza (Park et al., 2019; Shaman \& Kohn, 2009; Lowen \& Steel, 2014). The authors detected seasonality in influenza over tropical and subtropical regions and reported that flu viruses are not easily transmitted in hot and humid conditions. It is also important to mention that an earlier type of coronavirus, severe acute respiratory syndrome coronavirus (SARS-CoV), was unable to survive in higher temperatures (Bukhari \& Jameel, 2020). However, no seasonality has been established until now for coronaviruses. Bukhari and Jameel 
(2020) discussed that the number of positive COVID19 cases per capita is lower in some selected tropical countries compared to the United States and several European countries. The authors also hypothesized that the lower number of cases in tropical countries might be due to warm, humid conditions, under which the spread of the virus might be slower, as has been observed for other viruses (Lowen \& Steel, 2014). Wang et al. (2020) and references therein reported that $R_{0}$ of COVID-19 was reduced in conditions of high temperature and moisture for 100 Chinese cities with more than 40 cases. A possible reason is that the influenza virus is more stable in cold temperatures, as respiratory droplets remain airborne longer in dry air (Lowen \& Steel, 2014). Moreover, cold and dry weather environments can also weaken the human immune system and make individuals more susceptible to the virus (Kudo et al., 2019). Qi et al. (2020) examined the relations of daily mean temperature and relative humidity with the daily count of COVID-19 cases in 30 Chinese provinces from December 2019 to mid-February 2020 and found a significant negative association between weather parameters and COVID-19 cases. The authors noted that every $1{ }^{\circ} \mathrm{C}$ increase in mean temperature led to a decrease in the daily confirmed cases.

Hornyak (2020) reported that the death rate due to the COVID-19 pandemic is 4.5 times higher in highly polluted counties in the United States as compared to low-pollution regions. The author also reported that an increase of only one microgram per cubic meter of fine particulate matter (PM2.5) is associated with a $15 \%$ increase in the COVID-19 death rate. Wu et al. (2020) reported that the long-term average exposure to PM2.5 increases the risk of COVID-19 deaths in the United States. Particulate matter less than $10 \mu \mathrm{m}$ in diameter poses a risk for health problems related to heart or lung disease, aggravated asthma, decreased lung function, and increased respiratory symptoms such as coughing or difficulty breathing. $\mathrm{NO}_{2}$ is primarily emitted into the atmosphere from the burning of fuel, vehicle emissions, power plants, etc. It also affects the human respiratory system. Longer exposures to high concentrations of $\mathrm{NO}_{2}$ may contribute to the development of asthma and potentially increase susceptibility to respiratory infections. Both particulate matter and $\mathrm{NO}_{2}$ are harmful to the respiratory system, and the average values of $\mathrm{NO}_{2}$ concentrations are generally higher over the USA and European countries in which a large number of mortalities are seen due to COVID-19.

The COVID-19 outbreak has severely impacted the world economy, including India, which has been further aggravated under lockdown conditions. Most of the commercial flights, ships, public transport, and other vehicles are stopped under lockdown conditions, including industrial production and manufacturing units. However, at the same time, this lockdown scenario has led to less pumping of various harmful gases like PM and other pollutants into the atmosphere. The distribution of aerosol particles also strongly influences the weather and climate conditions. On a continental scale, aerosols reduce surface insolation and weaken the land-ocean thermal contrast, thus inhibiting the development of monsoons (Li et al., 2016). Locally, aerosol radiative effects alter the thermodynamic stability and convective potential of the lower atmosphere, leading to reduced temperatures, increased atmospheric stability, and weakened wind and atmospheric circulation. Moreover, the atmospheric thermodynamic state, which determines the formation of clouds, convection, and precipitation, may also be altered by aerosols serving as cloud condensation nuclei or ice nuclei ( $\mathrm{Li}$ et al., 2016).

The objective of this study is first to understand the connection between the time-varying value of $R_{0}$ for COVID-19 transmission and tropical and midlatitude atmospheric conditions. The study also assesses the impact of lockdowns on atmospheric and air quality parameters. Section 2 discusses brief details about COVID-19 transmission in India. The next section shows the results and a discussion that briefly summarizes the effects of COVID-19 and lockdowns on atmospheric parameters, followed by the conclusion in the last section.

\section{COVID-19 Transmission in India}

COVID-19 originated from the subtropical regions in the winter period and was further transmitted globally. The initial COVID-19 cases in India 
were detected after the winter monsoon period, and quickly expanded over most of the states in India. India is the second most populous country in the world after China, and the population of India is around 1.3 billion. The discussion of COVID-19 in India is essential due to the large population which is believed to be substantially affected by the COVID19 pandemic. The current situation in India is "total lockdown" in an attempt to slow the spread of COVID-19, initially on 25 March 2020 for 21 days and further extended until 3 May 2020. According to a World Health Organization (WHO) situation report, the first confirmed case of 2019-nCoV was reported in Kerala on 30 January 2020, having arrived from Wuhan, China (https://www.who.int/india/emergencies/india-situation-report). The Government of India (GoI) has issued travel advisories requesting the public to refrain from travel to China and that anyone with a travel history since 15 January 2020 from China will be quarantined on return. In the months of April and May, most of the Indian landmass is influenced by extreme heat and pre-monsoon showers followed by summer monsoon rainfall in the months of June-September.

\section{Data Used and Methodology}

\subsection{OMI-AURA Data}

The $\mathrm{NO}_{2}$ data are taken from the version 4.0 Ozone Monitoring Instrument (OMI) onboard NASA's Earth Observing System (EOS) Aura satellite. The OMI-AURA level-2 Standard Product (OMNO2) is used in this study. The data are available from the NASA Goddard Earth Sciences Data and Information Services Center (GES DISC). The major updates of version 4.0 are available on https://disc. gsfc.nasa.gov/datasets/OMNO2_003/summary. The OMNO2 files are stored in the EOS version 5 Hierarchical Data Format (HDF-EOS5). Each level-2 file contains data from the daylight portion of an orbit ( $\sim 53 \mathrm{~min}$ ). There are approximately 14 orbits per day. More details of this product are given by Krotkov et al. (2019).

\subsection{CAMS Reanalysis}

The Copernicus Atmosphere Monitoring Service (CAMS) reanalysis is the latest global reanalysis data set of atmospheric composition produced by the European Centre for Medium-Range Weather Forecasts (ECMWF), consisting of three-dimensional time-consistent atmospheric composition fields, including aerosols and chemical species (Inness et al., 2019). The CAMS reanalysis is the outcome of the experience gained during the production of the earlier Monitoring Atmospheric Composition and Climate (MACC) reanalysis and CAMS interim reanalysis. Various satellite retrievals including total column $\mathrm{CO}$, tropospheric column $\mathrm{NO}_{2}$, aerosol optical depth (AOD), and total column, partial column, and profile ozone retrievals were assimilated in the CAMS reanalysis using ECMWF's Integrated Forecasting System. In this study, the near-real-time global model analyses are obtained from the CAMS model.

\subsection{Methodology}

Cori et al. (2013) developed a ready-to-use tool for estimating $R_{0}$ from incidence time series. This tool produces novel, statistically robust analytical estimates of $R$ and incorporates uncertainty in the distribution of the serial interval (the time between the onset of symptoms in a primary case and the onset of symptoms in secondary cases). To estimate the value of $R_{0}$, the "EpiEstim" package in $\mathrm{R}$ programming language has been used in this study which implements a Bayesian approach for quantifying transmissibility over time during an epidemic (Cori et al., 2013; Wallinga \& Teunis, 2004). This package makes use of the serial interval distribution and is also able to directly incorporate uncertainty in serial interval distribution estimates.

To understand the impacts of lockdown conditions on the weather and air quality parameters, surface temperature, humidity, aerosol optical depth (AOD), PM2.5 (diameter less than $2.5 \mu \mathrm{m}$ ) and PM10 (diameter less than $10 \mu \mathrm{m}$ ), nitrogen dioxide $\left(\mathrm{NO}_{2}\right)$, and carbon monoxide $(\mathrm{CO})$ available from space-borne sensors and numerical weather prediction (NWP) models are used. Two broad comparisons 
are performed in this study, which is mainly focused on the impact of global/local lockdowns in 2020 as compared to 2019 and the impact of Indian lockdowns on air quality conditions over the Indian landmass.

\section{Results and Discussion}

\subsection{Reproduction Number for COVID-19}

The daily confirmed cases of COVID-19 in India from 12 March 2020 to 16 April 2020 are depicted in Fig. 1a. The total number of confirmed cases surpasses 50 on 12 March 2020, and reaches 12,380 on 16 April 2020. Figure 1a shows that the maximum number of daily new cases was 200 until 1 April 2020 under the total lockdown conditions, initiated partially on 22 March 2020 as "Janta Curfew" and further as "Country lockdown". The number of new cases of COVID-19 increased rapidly after 1 April 2020 over India. The country-wide lockdown continued as a preventive measure until 3 May 2020. The estimates of the instantaneous $R_{0}$ over sliding weekly windows are shown in Fig. 1b. The light blue region bounded by black lines shows the 95\% credible intervals (CI) from 19 March 2020 to 16 April 2020, and the mean value of $R_{0}$ is represented by the red line. The peak value of $R_{0}$ is noted as 2.35 (95\% CI 2.11-2.57) on 23 March 2020. It is important to note here that the value of $R_{0}$ is significantly reduced after lockdowns over India from 25 March 2020 to 1 April 2020. The value of $R_{0}$ is increased further after 1 April 2020 over India. For this period, the value of $R_{0}$ is greater than 1 , indicating that the epidemic was not yet over.

The scatter plot of $R_{0}$ against mean daily temperature and relative humidity for tropical $\left(30^{\circ} \mathrm{S}-\right.$ $\left.30^{\circ} \mathrm{N}\right)$ and mid-latitude $\left(60^{\circ} \mathrm{S}-30^{\circ} \mathrm{S}\right.$ and $30^{\circ} \mathrm{N}-$ $60^{\circ} \mathrm{N}$ ) regions is shown in Fig. 2. The total number of daily confirmed cases is used here to estimate the time-varying value of $R_{0}$ for a country lying in tropical and mid-latitude regions. Figure $2 \mathrm{a}$ and $\mathrm{b}$

(a)

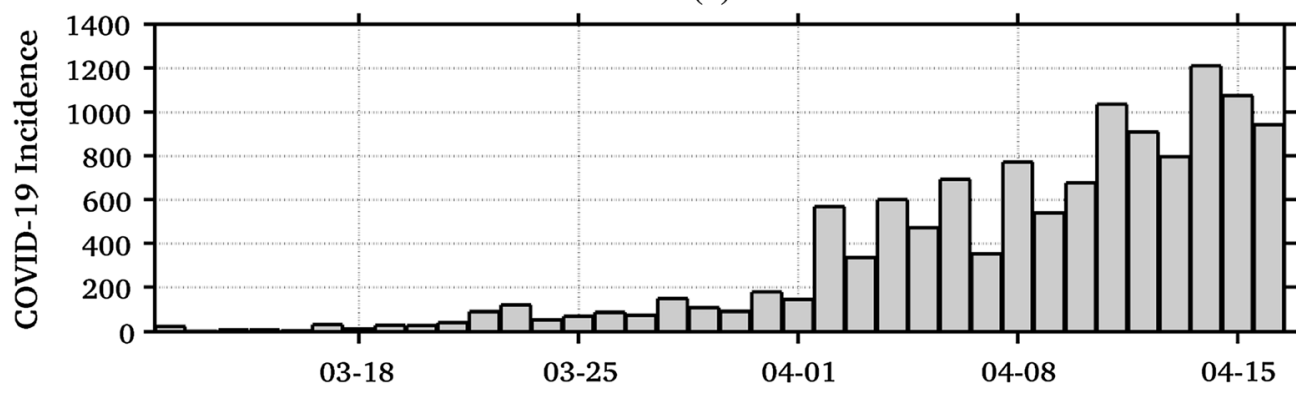

(b)

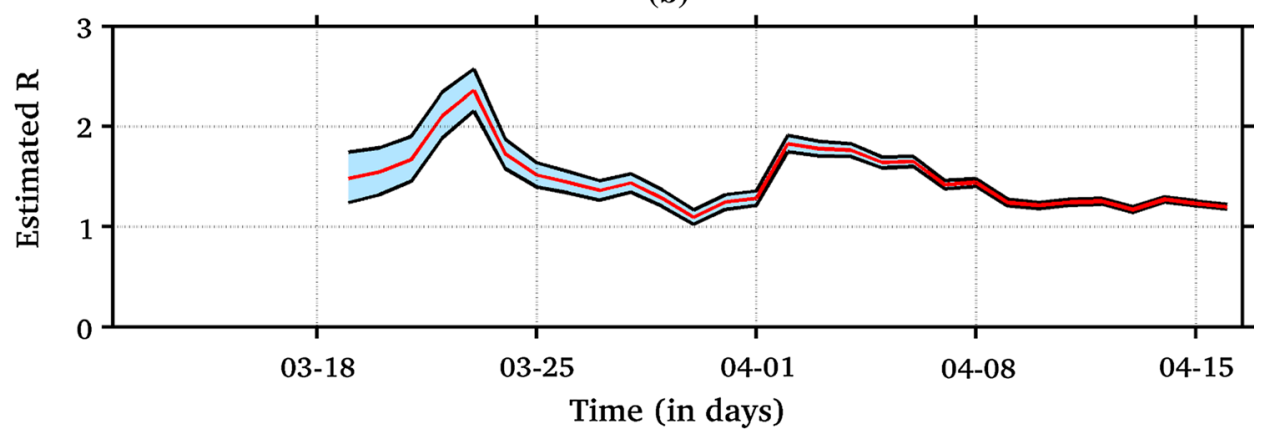

Figure 1

a The total number of confirmed cases of COVID-19 in India from 12 March 2020 to 16 April 2020. b The daily estimates of the reproduction numbers $\left(R_{0}\right)$ over sliding weekly windows. The red lines show the posterior mean, and the light blue region bounded by black lines shows the 95\% credible intervals 
(a)

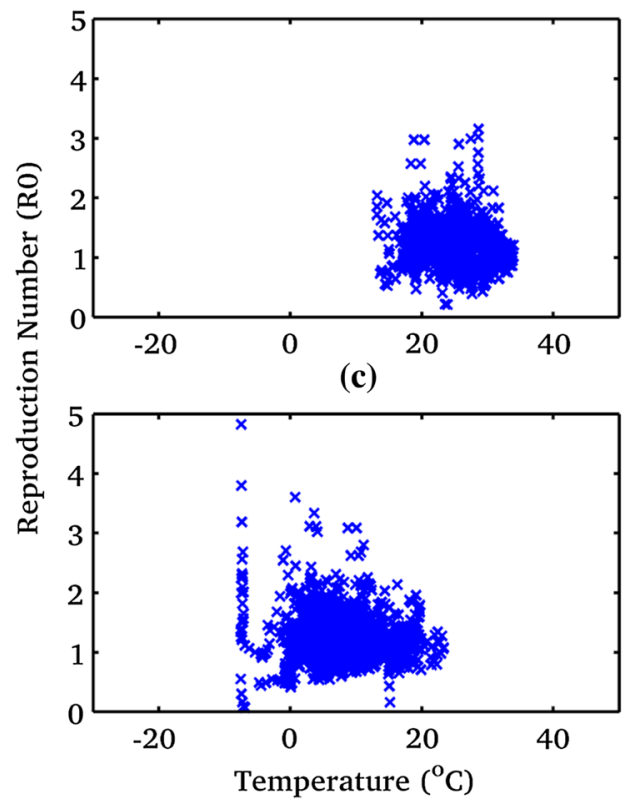

(b)

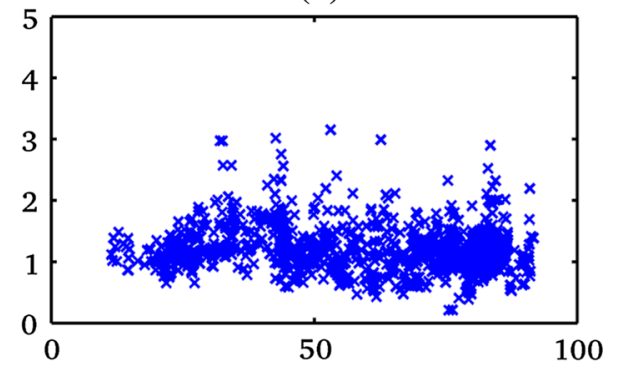

(d)

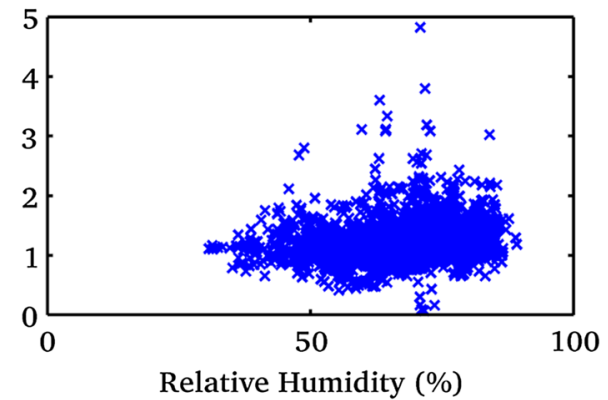

Figure 2

Scatter plot of $R_{0}$ against daily mean a temperature and $\mathbf{b}$ relative humidity for tropical countries. Scatter plot of $R_{0}$ against daily mean c temperature and $\mathbf{d}$ relative humidity for mid-latitude countries. A higher value of $R_{0}$ represents a larger spread of COVID-19 over the study area

suggests that $R_{0}$ values are mostly distributed in the temperature range of $10-40{ }^{\circ} \mathrm{C}$ and in the relative humidity range of $10-95 \%$ over tropical regions. The mean value of $R_{0}$ is around 1.2 , and varies from 0.2 to 3.2 over tropical countries. The scatter plots of $R_{0}$ against mean temperature and relative humidity for mid-latitude countries are depicted in Fig. 2c and d, respectively. Figure $2 \mathrm{c}$ and d clearly show that the mean temperature is significantly lower and the mean relative humidity value is higher in mid-latitude countries. The mean value of $R_{0}$ is 1.3 , and varies from 0.1 to 4.8 over mid-latitude countries. It suggests that a few mid-latitude regions are highly influenced, as represented by high $R_{0}$ values. The mean values of temperature and relative humidity are around $6{ }^{\circ} \mathrm{C}$ (in the range of -10 to $24{ }^{\circ} \mathrm{C}$ ) and around $65 \%$ (in the range of $60-95 \%$ ) over midlatitude countries. It is also important to note that a few countries have a very high value of $R_{0}$, and lie in areas of low-temperature and high-moisture conditions. The global transmission of the COVID-19 virus caused lockdown conditions in most of the countries that had been imposed in a few countries earlier. The impacts of global/Indian lockdowns due to COVID19 on atmospheric parameters are discussed in the next subsection.

\subsection{Atmospheric Parameters Under Lockdown Conditions}

Figure 3 shows the temporal variation in the mean values of surface temperature, relative humidity, PM2.5, PM10, integrated CO, and AOD extracted over the Indian landmass for 2019 and 2020. Figure $3 \mathrm{a}$ shows lower values of surface temperature over the Indian landmass beyond 7 March 2020 and noteworthy changes after 25 March 2020 as compared to 2019. However, no noteworthy changes are found in the months of January and February. The slight reduction in surface temperature in mid-March may be the influence of the global lockdown that was earlier than Indian lockdowns (25 March 2020). This reduction in mean temperature is due to the combined reduction of aerosol particles, trace gases, etc. It is 
(a)

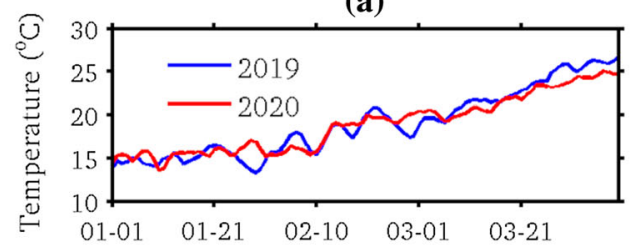

(c)

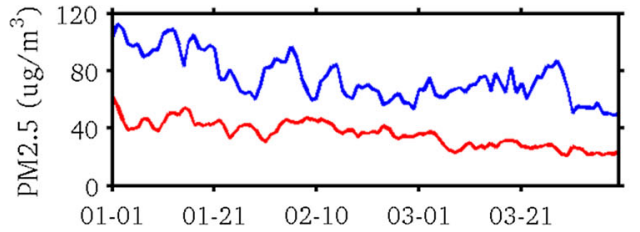

(e)

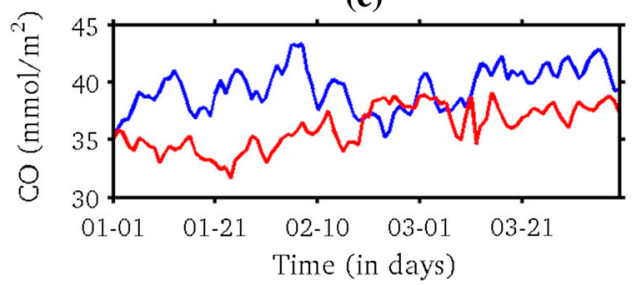

(b)

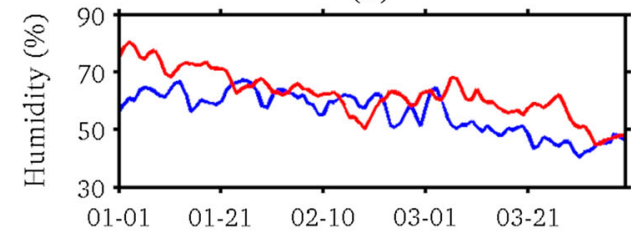

(d)

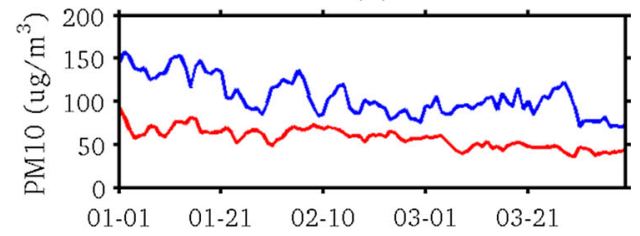

(f)

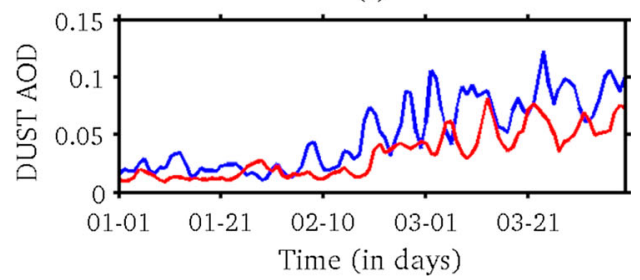

Figure 3

Temporal variation in mean value of a surface ( $2 \mathrm{~m}$ ) temperature, b surface relative humidity, $\mathbf{c}$ PM2.5, d PM10, e CO, and f dust AOD over the Indian landmass during 2019 and 2020

also observed from Fig. $3 \mathrm{~b}$ that there is a slightly higher mean relative humidity value in 2020 as compared to 2019. The time series of PM2.5 (Fig. 3c) and PM10 (Fig. 3d) suggest that the values of fine and coarse particle distribution are generally less in 2020 than in 2019. This impact is mainly due to global lockdowns due to COVID-19. The mean values of $\mathrm{CO}$ and dust AOD also show a reduction over India in 2020 in comparison to 2019. Overall, these model analysis variables suggest that noteworthy changes are detected in 2020 as compared to 2019, obviously indicating the impact of reduced anthropogenic activities during global lockdowns.

Figures 4 and 5 show PM2.5 analysis from the CAMS model and $\mathrm{NO}_{2}$ measurement from the OMI sensors to reveal the effects of lockdown over India. A country-level lockdown was announced on 25 March 2020, after an experimental voluntary public (Janta) curfew on 22 March 2020 and subsequent partial lockdowns on 23 and 24 March 2020. The time period of 3 March to 20 March is defined as "pre-lockdown", and the time period of 25 March-11 April is defined as "lockdown" duration. Figure 4 shows that a significantly higher value of PM2.5 is observed over the Indo-Gangetic plain during the prelockdown period as compared to the lockdown period. Slightly higher PM2.5 values are observed over the south-west and south-east parts of India during the lockdown period as compared to the prelockdown period. The slightly higher PM2.5 values during the lockdown may be largely explained by the precipitation which occurred during the pre-lockdown period over these regions. Significantly higher PM2.5 values are observed over north-east India in the pre-lockdown period as compared to the lockdown period. This suggests that lockdowns over the Indian region due to COVID-19 transmission significantly improved air quality. Similar to PM2.5, values of PM10 are also significantly reduced over the IndoGangetic plain region due to lockdown. Interestingly, the results also indicate slightly increased values of 
(a)

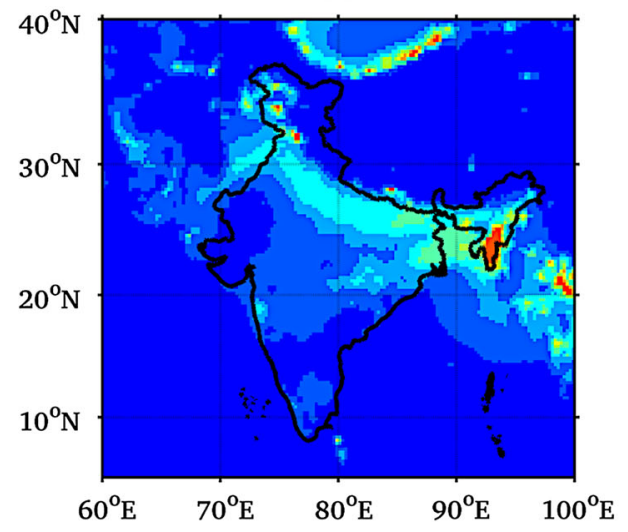

(b)

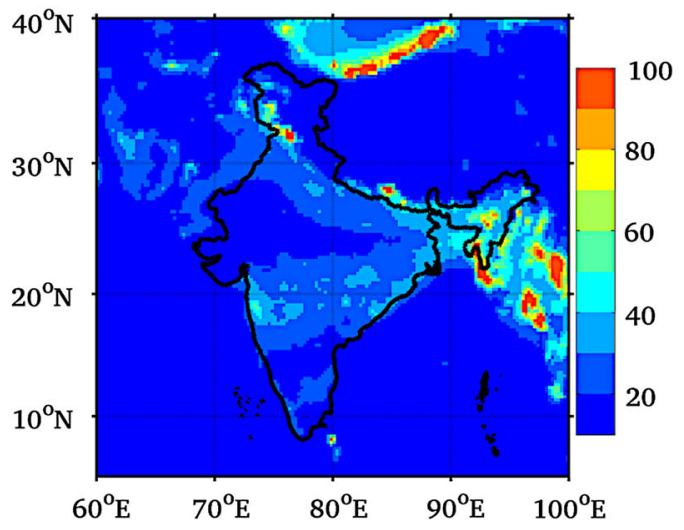

Figure 4

Spatial distribution of PM2.5 over Indian and nearby regions during a pre-lockdown and b lockdown period. The PM2.5 analyses are taken from CAMS near-real-time products

(a)

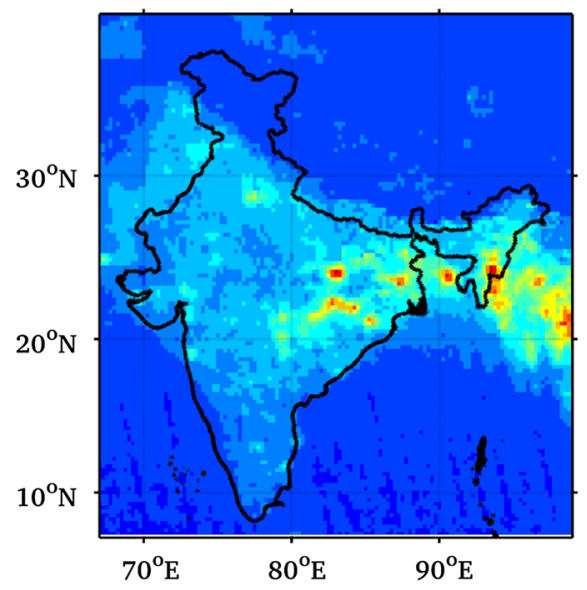

(b)

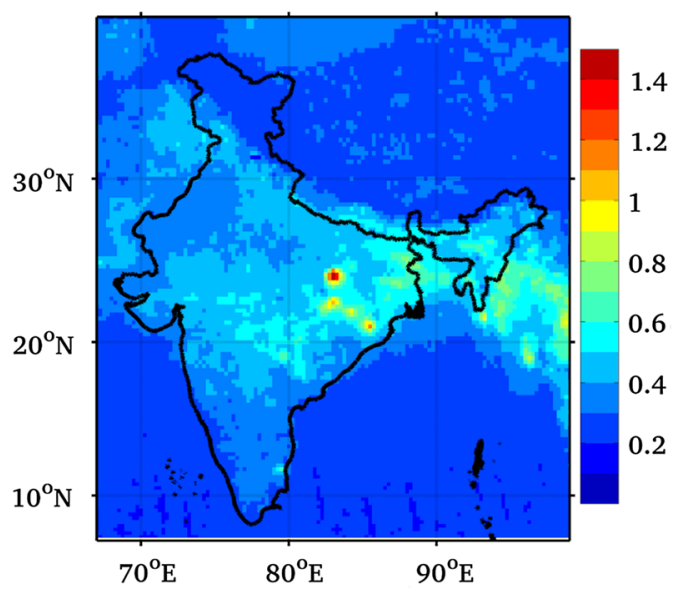

Figure 5
PM over China. A possible reason may have been a resumption of lockdown in China during this period.

$\mathrm{NO}_{2}$ is mainly generated by combustion processes from anthropogenic pollution sources (including energy production, transportation, and other industrial activities), and it is toxic in high concentrations at the surface. The spatial distribution of $\mathrm{NO}_{2}$ available from OMI during the pre-lockdown and lockdown period is shown in Fig. 5. The figure depicts significantly lower values of $\mathrm{NO}_{2}$ over the Indian landmass during the lockdown period compared to the pre-lockdown period. These reductions in $\mathrm{NO}_{2}$ concentration are noteworthy over the northern and western part of India. Moreover, a few central India locations showed higher values of $\mathrm{NO}_{2}$ in both pre-lockdown and lockdown period, which are due to operational power plants over these regions. Overall, the present investigation clearly shows that the air quality of India and nearby regions was improved significantly during the lockdown period as compared to the pre-lockdown period for 2020. 


\section{Conclusion}

The present study reveals that the $R_{0}$ value of COVID-19 transmission is significantly less over the tropical regions as compared to mid-latitude regions. Moreover, the high value of $R_{0}$ is also linked with temperature and moisture over tropical and mid-latitude conditions. The results suggest that lockdown conditions due to COVID-19 transmission over India led to changes in atmospheric parameters and air quality. Results also suggest that the values of particulate matter and $\mathrm{NO}_{2}$ are significantly modified in lockdown conditions. Furthermore, lower aerosol concentrations may also alter weather and climate conditions. These significant modifications in air quality may also affect solar radiation conditions and rainfall patterns. The reduction in aerosol particles may locally reduce the number of cloud condensation nuclei (CCN), which may result in less cloud cover and more intense solar radiation. Further study of these processes is also important to assess the role of this global/local lockdown on large-scale atmospheric processes such as the Indian monsoon, cloud processes, and modifications in extreme rainfall.

\section{Acknowledgements}

Thanks are due to the European Centre for Disease Prevention and Control, an agency of the European Union, for providing the cases of COVID-19 infection and deaths used in this study (https://www.ecdc. europa.eu/en/publications-data/download-todays-datageographic-distribution-covid-19-cases-worldwide). CAMS near-real-time analysis was downloaded from the ECMWF server (https://apps.ecmwf.int/ datasets/data/cams-nrealtime/levtype $=$ sfc/). The $\mathrm{NO}_{2}$ observations from OMI are available from the EarthData server (https://search.earthdata.nasa.gov/) after login. The EpiEstim: Estimate Time-Varying Reproduction Numbers from Epidemic Curves package was downloaded from https://cran.r-project.org/web/ packages/EpiEstim/index.html to simulate the reproduction number.
Publisher's Note Springer Nature remains neutral with regard to jurisdictional claims in published maps and institutional affiliations.

\section{REFERENCES}

Biggerstaff, M., Cauchemez, S., Reed, C., Gambhir, M., \& Finelli, L. (2014). Estimates of the reproduction number for seasonal, pandemic, and zoonotic influenza: a systematic review of the literature. BMC Infectious Diseases, 14(1), 480.

Bukhari, Q., \& Yusuf, J. (2020). Will coronavirus pandemic diminish by summer?. Available at SSRN 3556998.

Cintrón-Arias, A., Castillo-Chávez, C., Betencourt, L., Lloyd, A. L., \& Banks, H. T. (2020). The estimation of the effective reproductive number from disease outbreak data. arXiv preprint arXiv:2004.06827.

Cori, A., Ferguson, N. M., Fraser, C., \& Cauchemez, S. (2013). A new framework and software to estimate time-varying reproduction numbers during epidemics. American Journal of Epidemiology, 178(9), 1505-1512.

Delamater, P. L., Street, E. J., Leslie, T. F., Yang, Y. T., \& Jacobsen, K. H. (2019). Complexity of the basic reproduction number (R0). Emerging Infectious Diseases, 25(1), 1.

Hornyak, T. (2020). Air pollution can worsen the death rate from COVID-19. Eos. https://doi.org/10.1029/2020EO142660

Inness, A., Ades, M., Agusti-Panareda, A., Barré, J., Benedictow, A., Blechschmidt, A. M., Dominguez, J. J., et al. (2019). The CAMS reanalysis of atmospheric composition. Atmospheric Chemistry and Physics, 19(6), 3515-3556.

Isaifan, R. J. (2020). The dramatic impact of Coronavirus outbreak on air quality: Has it saved as much as it has killed so far? Global Journal of Environmental Science and Management, 6, 275-288.

Krotkov, N. A., Lamsal, L. N., Marchenko, S. V., Bucsela, E. J., Swartz, W. H., \& Joanna Joiner and the OMI core team. (2019). OMI/Aura Nitrogen Dioxide (NO2) Total and tropospheric column 1-orbit L2 Swath $13 \times 24$ km V003, Greenbelt, MD, USA, Goddard Earth Sciences Data and Information Services Center (GES DISC). Accessed [Data Access Date]. https://doi.org/10. 5067/Aura/OMI/DATA2017.

Kudo, E., Song, E., Yockey, L. J., Rakib, T., Wong, P. W., Homer, R. J., \& Iwasaki, A. (2019). Low ambient humidity impairs barrier function and innate resistance against influenza infection. Proceedings of the National Academy of Sciences, 116(22), 10905-10910.

Li, Z., Lau, W.K.-M., Ramanathan, V., Wu, G., Ding, Y., Manoj, M. G., Liu, J., et al. (2016). Aerosol and monsoon climate interactions over Asia. Reviews of Geophysics, 54(4), 866-929.

Liu, Y., Gayle, A. A., Wilder-Smith, A., \& Rocklöv, J. (2020). The reproductive number of COVID-19 is higher compared to SARS coronavirus. Journal of Travel Medicine, 27, taaa021.

Lowen, A. C., \& Steel, J. (2014). Roles of humidity and temperature in shaping influenza seasonality. Journal of Virology, 88(14), 7692-7695.

Obadia, T., Haneef, R., \& Boëlle, P.-Y. (2012). The R0 package: a toolbox to estimate reproduction numbers for epidemic outbreaks. BMC Medical Informatics and Decision Making, 12(1), 147. 
Park, J. E., Son, W. S., Ryu, Y., Choi, S. B., Kwon, O., \& Ahn, I. (2019). Effects of temperature, humidity, and diurnal temperature range on influenza incidence in a temperate region. Influenza and Other Respiratory Viruses, 14, 11-18.

Qi, H., Xiao, S., Shi, R., Ward, M. P., Chen, Y., Tu, W., Su, Q., Wang, W., Wang, X., \& Zhang, Z. (2020). COVID-19 transmission in Mainland China is associated with temperature and humidity: a time-series analysis. medRxiv.

Sahin, S., Boado-Penas, M. C., Constantinescu, C., Eisenberg, J., Henshaw, K., Hu, M., Wang, J., \& Zhu, W. (2020). COVID-19 in a social reinsurance framework: Forewarned is forearmed. arXiv preprint arXiv:2004.04835.

Shaman, J., \& Kohn, M. (2009). Absolute humidity modulates influenza survival, transmission, and seasonality. Proceedings of the National Academy of Sciences, 106(9), 3243-3248.

Van den Driessche, P., \& Watmough, J. (2008). Further notes on the basic reproduction number. Mathematical Epidemiology (pp. 159-178). Berlin: Springer.
Wallinga, J., \& Teunis, P. (2004). Different epidemic curves for severe acute respiratory syndrome reveal similar impacts of control measures. American Journal of Epidemiology, 160(6), 509-516.

Wang, J., Tang, K., Feng, K., \& Lv, W. (2020). High temperature and high humidity reduce the transmission of covid-19. Available at SSRN 3551767.

Wu, X., Nethery, R. C., Sabath, B. M., Braun, D., \& Dominici, F. (2020). Exposure to air pollution and COVID-19 mortality in the United States. medRxiv.

Zhang, S., Diao, M. Y., Yu, W., Pei, L., Lin, Z., \& Chen, D. (2020). Estimation of the reproductive number of novel coronavirus (COVID-19) and the probable outbreak size on the Diamond Princess cruise ship: a data-driven analysis. International Journal of Infectious Diseases, 93, 201-204.

(Received December 23, 2020, revised January 19, 2021, accepted June 10, 2021, Published online June 29, 2021) 